\title{
Supporting Information to Migration of Liquid Bridges at the Interface of Spheres and Plates with an Imposed Thermal Gradient
}

Qingwen Dai*, Zhejun Chong, Wei Huang, and Xiaolei Wang

National Key Laboratory of Science and Technology on Helicopter Transmission,

Nanjing University of Aeronautics \& Astronautics, Nanjing 210016, China

*Corresponding author: Qingwen Dai, daiqingwen@nuaa.edu.cn

Number of pages: 1

Number of figures: 1

Fig. S1 shows the residual liquids adhered on sphere surfaces under different materials of (1) GCr15, (2) $\mathrm{Si}_{3} \mathrm{~N}_{4}$, and (3) PTFE; and GCr15 with different diameters of (4) $\mathrm{d}=10$ $\mathrm{mm}$, (5) $\mathrm{d}=12 \mathrm{~mm}$, and (6) $\mathrm{d}=14 \mathrm{~mm}$, the experimental conditions are as follows: thermal gradient of $3.64^{\circ} \mathrm{C} / \mathrm{mm}$, gap of $1.5 \mathrm{~mm}$, and viscosity of $100 \mathrm{mPa} \cdot \mathrm{s}$.
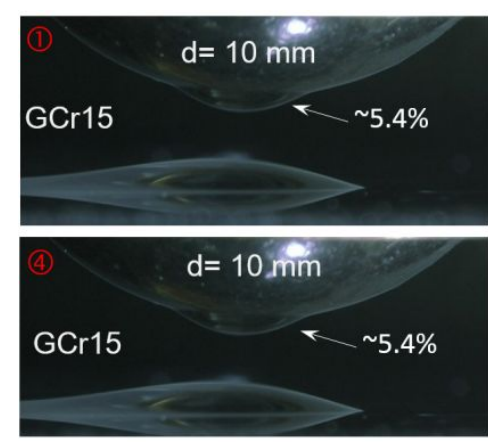
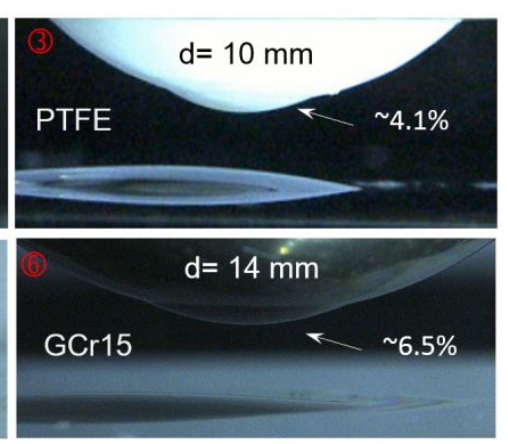

Fig. S1 Residual liquids adhered on sphere surfaces under varying experimental conditions. 